\title{
Therapeutic itinerary of people with leprosy: paths, struggles, and challenges in the search for care
}

\author{
Itinerário terapêutico das pessoas com hanseníase: caminhos, lutas e desafios em busca do cuidado \\ Itinerario terapéutico de personas con lepra: caminos, luchas y desafíos en busca de atención
}

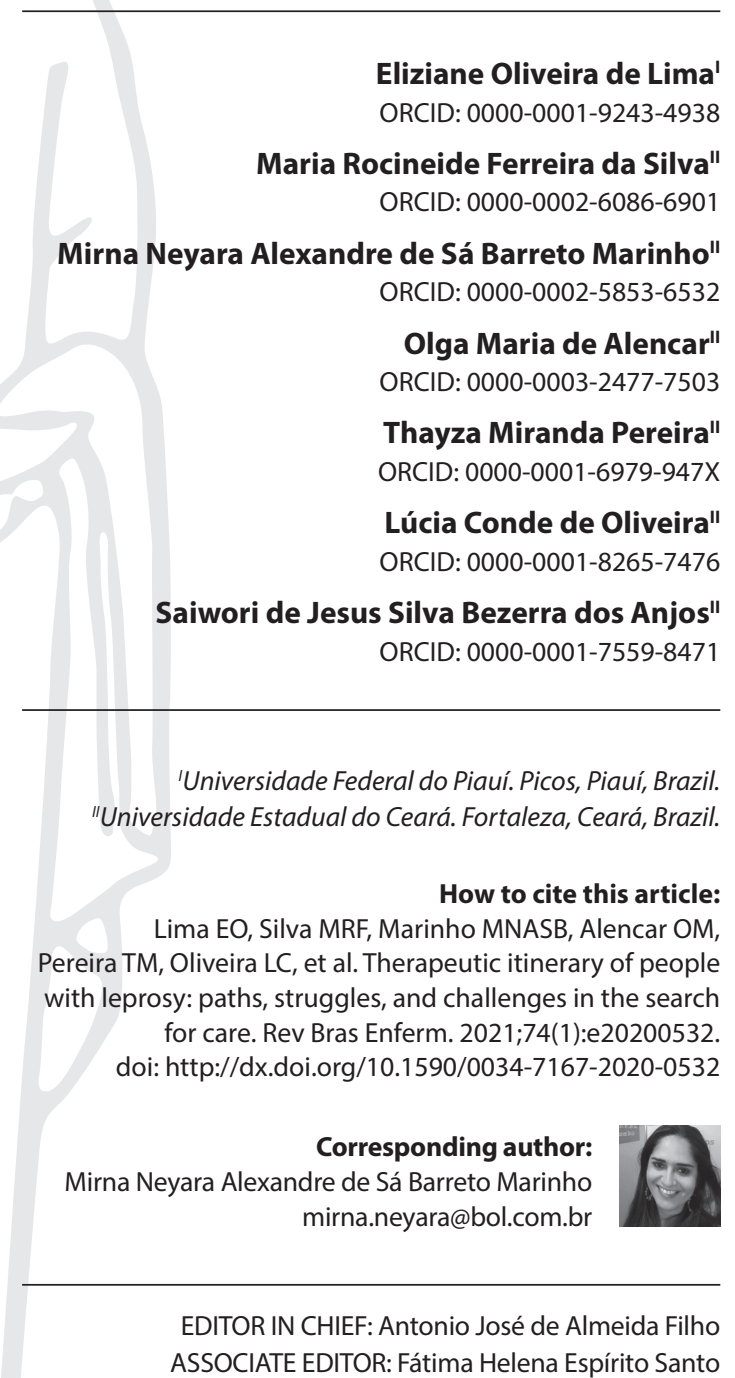

Submission: 07-29-2020

\begin{abstract}
Objectives: to understand how the therapeutic itineraries of people affected by leprosy are processed. Methods: this is a descriptive, qualitative study, conducted in April 2018 in Barão de Grajaú in Maranhão, with interviews in the form of narratives of seven patients who had a late leprosy diagnosis. Results: the search for diagnosis is a major difficulty in accessing health services, resulting in a late diagnosis and, consequently, with the presence of visible deformities. It was noticed that the health units do not have a flow, nor protocols for comprehensive treatment, and these people are referred to a referral unit in another state to perform sputum smear microscopy. Final Considerations: leprosy control actions need reformulations that seek the relationship between operational activities, epidemiological indicators and risk factors, in accordance with the real needs of each region, thus highlighting the gaps evidenced in the therapeutic itineraries.

Descriptors: Leprosy; Delayed Diagnosis; Access to Health Care; Primary Health Care; Family Health Strategy.
\end{abstract}

\section{RESUMO}

Objetivos: compreender como se processam os itinerários terapêuticos das pessoas acometidas pela hanseníase. Métodos: estudo descritivo, qualitativo, realizado em abril de 2018, em Barão de Grajaú, no Maranhão, com entrevistas no formato de narrativas de sete pacientes que tiveram diagnóstico tardio de hanseníase. Resultados: a busca pelo diagnóstico se configura como uma grande dificuldade de acesso aos serviços de saúde, resultando no diagnóstico tardio e, consequentemente, na presença de deformidades visíveis. Percebeu-se que as unidades de saúde não possuem um fluxo nem protocolos para tratamento integral, sendo que essas pessoas são encaminhadas para unidade de referência em outro estado para a realização da baciloscopia. Considerações Finais: as ações de controle da hanseníase necessitam de reformulações que busquem a relação entre as atividades operacionais, indicadores epidemiológicos e os fatores de risco, em concordância com as reais necessidades de cada região, destacando-se, assim, as lacunas evidenciadas nos itinerários terapêuticos. Descritores: Hanseníase; Diagnóstico Tardio; Acesso aos Serviços de Saúde; Atenção Primária à Saúde; Estratégia Saúde da Família.

\section{RESUMEN}

Objetivos: comprender cómo se procesan los itinerarios terapéuticos de las personas afectadas por la lepra. Métodos: estudio descriptivo, cualitativo, realizado en abril de 2018, en Barão de Grajaú, Maranhão, con entrevistas en forma de narrativas de siete pacientes con diagnóstico tardío de lepra. Resultados: la búsqueda del diagnóstico es una gran dificultad para acceder a los servicios de salud, resultando en un diagnóstico tardío y en presencia de deformidades visibles. Se notó que las unidades de salud no cuentan con un flujo ni protocolos de tratamiento integral, y estas personas son derivadas a una unidad de referencia en otro estado para realizar microscopía de baciloscopia de esputo. Consideraciones Finales: las acciones de control necesitan reformulaciones que busquen la relación entre las actividades operativas, los indicadores epidemiológicos y los factores de riesgo, de acuerdo con las necesidades reales de cada región, destacando las brechas que se evidencian en los itinerarios terapéuticos. Descriptores: Lepra; Diagnóstico Tardío; Accesibilidad a los Servicios de Salud; Atención Primaria de Salud; Estrategia de Salud Familiar. 


\section{INTRODUCTION}

Despite the efforts of government agencies and non-governmental organizations to implement various public policies, leprosy, of ancient origin, remains in the $21^{\text {st }}$ century as a major challenge to public health worldwide ${ }^{(1)}$. This is an infectious, chronic disease, with high power to produce prejudice, stigma and social exclusion ${ }^{(2)}$.

Leprosy is a disease associated with conditions of poverty that worsens with the situation of inequality, fitting into neglected diseases, affecting more than one billion people worldwide, with Brazil ranking second in this ranking ${ }^{(3)}$. Therefore, this is considered an important evidence for decision-making by the Brazilian State.

The Ministry of Health, basing itself on the global strategy for the elimination of leprosy, which aimed to accelerate'action towards a world without leprosy', developed this national plan as one of the program guidelines based on the pillars of strengthening control and government partnership, combating leprosy and its implications and tackling discrimination with social inclusion promotion, so that it could be implemented in all federal units in Brazil(4-5).

According to the 2020 epidemiological bulletin, between 2014 and $2018,140,578$ new leprosy cases were diagnosed in Brazil. Of these, $55.2 \%$ were male, $58.3 \%$ were declared mixed-race, $43.3 \%$ had incomplete elementary school and an average detection rate of 13.64 new cases per 100 thousand inhabitants ${ }^{(6)}$.

In 2019, of the total new diagnosed cases, $78.2 \%$ were classified as multibacillary, an infectious form of the disease, and $82 \%$ were assessed for the degree of physical disability in the diagnosis, with a parameter considered regular for this indicator ${ }^{(6)}$.

Disability is a broad term that includes any impairment, activity limitation or restriction in a person's life. Therefore, it is necessary to determine the Disability Grading (DG) for each new case of multibacillary leprosy, with variations in the scale from 0 to 2 . Grade 0 is the determinant that no disability was found; grade 1 signals relevant changes in the eyes, hands and feet; grade 2 points to the presence of noticeable disabilities, such as bone resorption, lagophthalmos, ulcers, claws, among others ${ }^{(7)}$.

DG determination is closely related to the time of diagnosis. According to Leano et al. ${ }^{(8)}$, leprosy diagnosis presents some difficulties, so that the clinical picture can be confused with other skin diseases, which favors, for that, late diagnosis, physical disabilities and consequently the evolution of deformities.

Family Health Strategy (FHS) has been the main responsible for disease diagnosis and treatment across the country. Pereira et al. ${ }^{(9)}$ emphasize that incorporating surveillance and leprosy control actions is considered an important strategy performed in primary care, with the challenge of ensuring that all people have an equal opportunity to be diagnosed and treated.

In this direction, the question is: how does the search for diagnosis of people affected by leprosy occur? What difficulties did they encounter in this journey? What are the determining factors/processes for late diagnosis? To answer these questions, we used therapeutic itineraries (TIs) as a theoretical and methodological basis. TIs are an important means to understand people's health demands, which can be understood as the search for therapeutic care by individuals ${ }^{(10)}$.

TIs have been explored through different perspectives, often in a fragmented way, limited to the description of paths or flows, both through the formal system, search and offer through the health service network, as well as through the informal system, involving self-care and practices religious; however, with regard to programmatic flows, these do not always correspond to people's needs, and may result in unsuccessful pilgrimages by different health services ${ }^{(11)}$.

\section{OBJECTIVES}

To understand how the therapeutic itineraries of people affected by leprosy are processed.

\section{METHOD}

\section{Ethical aspects}

A study entitled "Podem até dizer que cura a pele, mas a hanseníase não tem cura: Itinerários terapêuticos de pessoas com hanseníase multibacilar" was submitted and approved by the Research Ethics Committee of Universidade Estadual do Ceará, respecting the ethical aspects provided for in the legislation current about research with human beings.

\section{Type of study}

This is a descriptive study with a qualitative approach, which used the Consolidated Criteria for Reporting Qualitative Research $(\text { COREQ })^{(12)}$, which has 32 items of guidance for qualitative research.

\section{Methodological procedures}

For location and subsequent contact of patients, the Community Health Workers (CHWs) of each micro-area of FHS supported this moment, including with participation in some visits. Data collection was carried out through an interview, with items that included user identification and two generating questions, namely: how was your path to learn about the disease? What path did you take to be taken care of?

\section{Study setting}

The research was developed in the rural and urban area of the municipality Barão de Grajaú, located in the east of Maranhão, with an estimated population of 18,820 people ${ }^{(13)}$. The municipality has 10 establishments in its health services infrastructure, one of which is a small municipal hospital with 30 beds and nine FHS teams (five in the rural area and four in the urban area). Regarding leprosy care, reference happens to the municipalities of São João dos Patos, Caxias and Presidente Dutra in Maranhão State; however, due to its proximity, users also seek the municipality of Floriano, in Piauí, through the Brazilian National Health Foundation (FUNASA - Fundação Nacional de Saúde) for sputum smear microscopy and consultation with a specialized physician.

\section{Participants}

The research participants were residents of the municipality, over 18 years of age diagnosed with multibacillary leprosy, who underwent treatment in the municipality and were registered in the Notifiable Diseases Information System (SINAN - Sistema de Informação de Agravos de Notificação) between 2001 and 2015. This 
time interval was chosen due to beginning of SINAN records in the Department of Informatics of the Brazilian Unified Health System (DATASUS - Departamento de Informática do Sistema Único de Saúde do Brasil) database. In the meantime, a total of 224 cases were notified, of which 116 were paucibacillary (PB) and 108 multibacillary (MB). However, when examining the notifications via the municipal system, only 170 were registered, being 73 PB and 97 MB. Thus, understanding this divergence, data from the municipal health system were considered due to the availability of documents for subsequent contact of $\mathrm{MB}$ patients.

Of the 97 people with MB leprosy, 73 completed treatment and met the inclusion criteria for the study, of which 39 were located and interviewed; some were no longer at the address provided and others did not appear at the agreed location, as scheduled. It is noteworthy that the itineraries described and analyzed were of people who had a late diagnosis, had reactional episodes, had a recurrence of the disease and a history of retreatment, resulting in seven participants.

\section{Data production}

Some interviews took place when participants were identified and others took place after scheduling the time and place most comfortable for them. Most of them occurred in their residences, others in churches close to the residences and also in Basic Health Units. They were recorded using a portable recorder individually. Objective information was obtained from secondary sources (SINAN) and updated at the time of the interview through a script prepared with questions of personal and socioeconomic data.

The interviews were transcribed and organized in the form of narratives, and through this, a corresponding dialogue was sought through people's speeches. This type of interview aims to encourage people to tell something about an important event in their lives and the social context ${ }^{(14)}$.

Seven narratives were used for data analysis, and this choice was made intentionally, selecting patients with a late leprosy diagnosis and consequently some neural impairment. These narratives were organized, also in figure format, using Inkscape, a professional quality vector graphics editor for Linux, Windows and macOS version 0.92.2 (2017) that were constituted in TI.

\section{Findings analysis}

Minayo's thematic analysis ${ }^{(15)}$ was used to treat the material obtained, with thematic units considering the following steps: (1) Pre-analysis, which consisted of choosing the material to be analyzed; (2) Text skimming, which consisted of constituting the corpus, formulating and reformulating hypotheses or assumptions, with transcription of the narratives and their identification in numerical order according to the participants' approach; (3) Constitution of the corpus in which the studied material was organized, using the criteria of qualitative validity: exhaustiveness, representativeness, homogeneity, pertinence; (4) Determination of the registration unit, the context unit, the clippings and the form of categorization, the coding modality and the more general theoretical concepts.

Theoretical support was made possible by ITs constituted by all the movements triggered by individuals in health prevention or recovery. They can mobilize different resources that include from home care, religious practices to the predominant networks such as primary care and emergency, i.e., it is equivalent to decision making, aiming at the diagnosis and or treatment of the disease, which builds a certain trajectory ${ }^{(16)}$.

Three categories of analysis were generated according to the empirical data provided by TI, namely: Pilgrimage in the search for leprosy diagnosis: a long way; Self-perception of clinical signs and suspicion of the disease by family and friends; Leprosy marks: leprosy reactions as enhancers of illness.

\section{RESULTS}

Next, we will present the subjects and the paths that patients took, many of them making access to health services and consequently care unfeasible.

P1 - J.E.F.S. - 60 years old, male, married, with incomplete elementary education, bricklayer, catholic, without fixed income, lives with five people in a residence built by the municipal government with five rooms.

TI P1 - He suspected of leprosy in 2013 when he lived and worked in Três Lagoas, in Mato do Grosso do Sul. At bath time at work, he noticed spots on his back, arms and ribs. This led him to look for the company's health service. The physician identified as an allergy and prescribed an ointment, used for several months, that relieved the itching, but the spots remained. On his break, he visited his family in Maranhão, and his brother suspected the disease. On return to work, the spots were exacerbated and he went to the physician three more times, who followed the previous procedure, which made him use ointment for more than seven months. In July 2014, after resignation, he returned to Maranhão with advanced symptoms (itching, numb feet, joint pain). He went to the BHU in Barão do Grajaú and at the consultation the physician requested a sputum smear microscopy (performed in Floriano, Piauí), with positive result for leprosy, and then he started treatment. In the first weeks of polychemotherapy (PCT), the patient felt a lot of pain and had to return to the unit, receiving referral to Floriano's private network, where he received prescriptions for thatlidomide and later prednisone. Figure 1 shows patient 1's Tl:

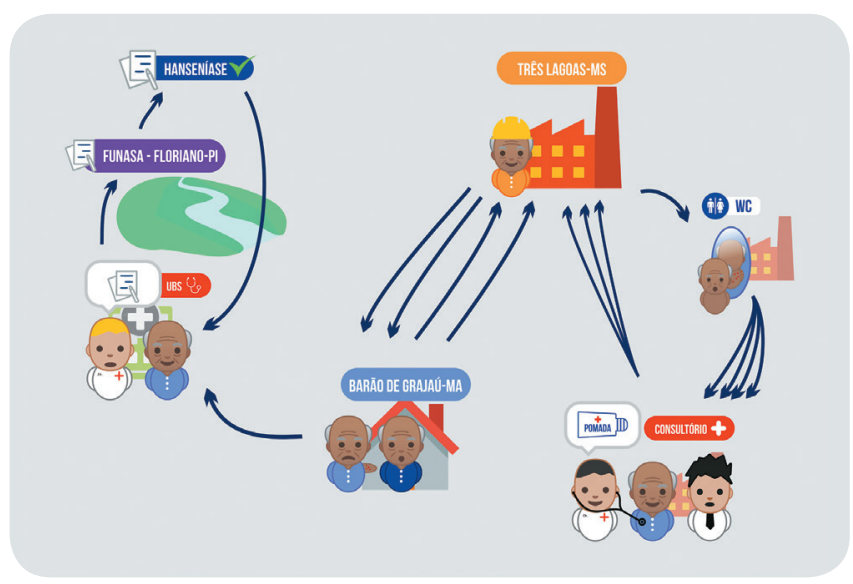

Figure 1 - P1's therapeutic itinerary

P2 - H.F.S. - 23 years old, male, single, studying higher education, Catholic, earning a minimum wage, lives with his parents in his own three-room house. 
TI P2 - It all started with a spot on his leg, which did not disappear, he even consulted with three physicians in town. In fourth consultation, the diagnosis was reached after tests in Floriano-PI, positive for leprosy. Treatment was carried out by the BHU health team from his municipality. Treatment was carried out in 2012, but until the collection period, the patient remained in follow-up, as the nodules were exacerbated in intervals, with an inflammatory process and episodes of fever and severe pain (SCI). The FHS physician referred him to a specialist from Floriano's private network and continues to consult every 30 days due to continuous use of $10 \mathrm{mg}$ prednisone, with dose changes to $20 \mathrm{mg}$.

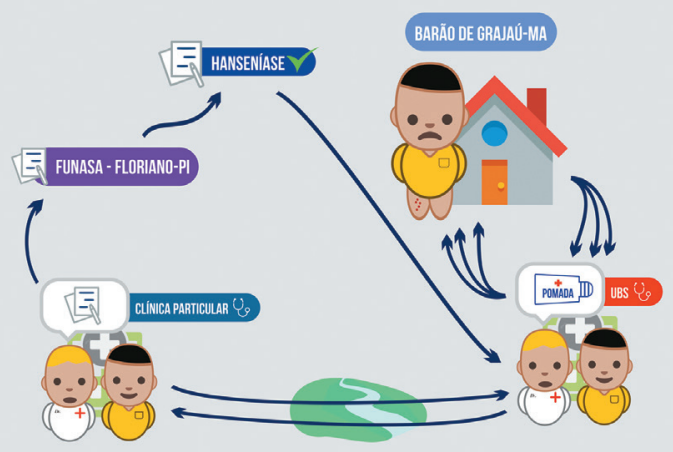

Figure 2 - P2's therapeutic itinerary

P3 - S.F.S. - 80 years old, male, married, with incomplete elementary school, farmer/retired, Catholic, income of two minimum wages, lives in his own house with six rooms and three more people.

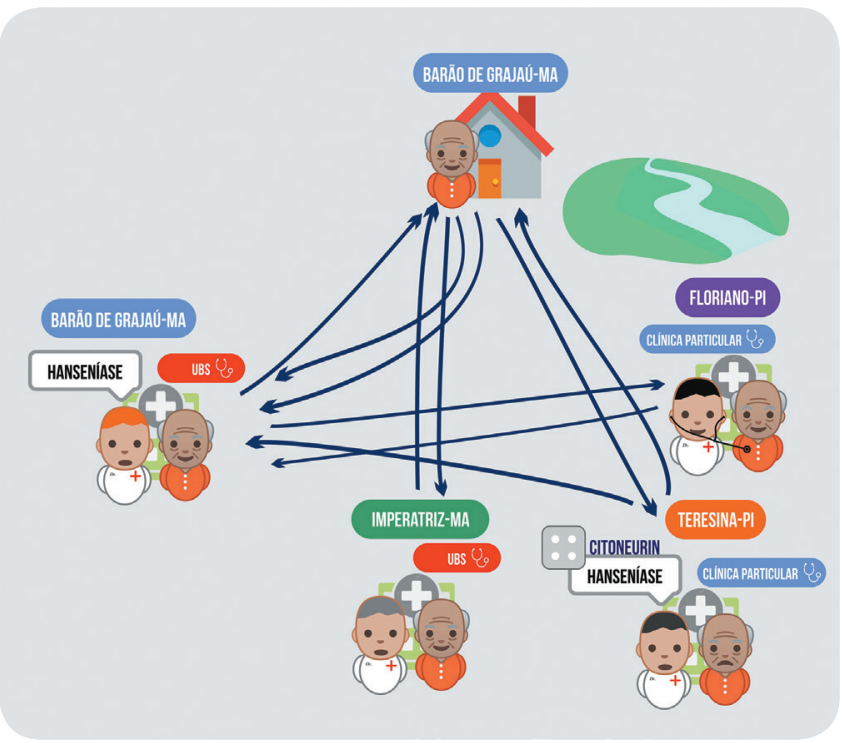

Figure 3 - P3's therapeutic itinerary

TI P3 - Pilgrimage started due to joint pain, he went to Teresina and the physician suspected of leprosy, but he gave injectable medication (citoneurin) for six months and asked for a return after use, but he was referred by the CHW in his area to the FHS physician in Barão de Grajaú. At that consultation, diagnosis was made and treatment started for six months, plus prednisone to reduce pain. Before finishing his treatment, he went to Imperatriz in Maranhão and there he sought a BHU to continue PCT. When assessing him, the physician realized that his therapeutic scheme was incompatible with the disease's clinical form, and told him that his treatment was wrong, in need of urgent change, as the disease was advanced. He requested a return to $\mathrm{BHU}$ to start treatment for a year. After three months of this new treatment, he returned to Barão de Grajaú, returning to FHS. The physician referred him to Floriano for consultation with a private specialist.

P4 - R.S.S. - 65 years old, single, uneducated, retired, a minimum wage, Catholic, lives with her daughter and six other people in an eight-room house.

TI P4 - She had prolonged contact with her daughter, who was diagnosed with leprosy in 2009, but only in 2014 did she learn that she also had the disease. She had a spot on her face, went to a private clinic in Floriano; the physician asked for an elbow exam, but twice she went to the FUNASA Health Unit, which is the referral center for leprosy, and was unable to do so. She returned to the appointment and the physician started treatment for six months. One year after her treatment was completed, she went to another physician, because the spot came back, and this time, smear microscopy was performed with a positive result, starting a 12-month treatment, and soon prednisone was added to reduce pain. A blister appeared at the spot, returning to the FUNASA health unit, and on that occasion the physician added thalidomide for four months.

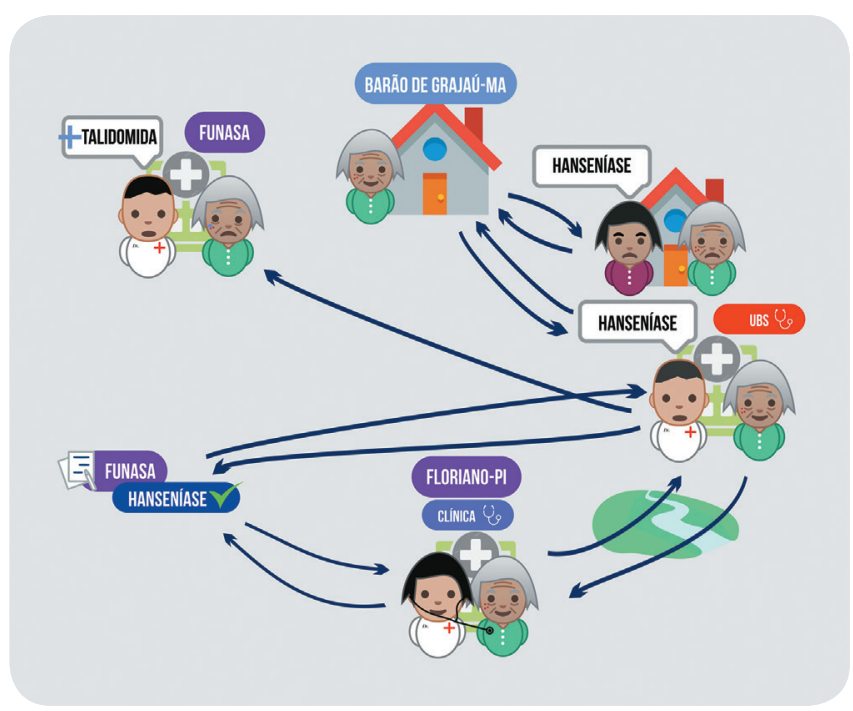

Figure 4 - P4's therapeutic itinerary

P5 - A.V.P.S. - 36 years old, female, married, complete higher education, teacher of early childhood education, catholic, income of 1.5 minimum wages, lives in her own house of five rooms.

TI P5 - She suspected the disease when she noticed spots on her body. She used ointment on her own, without improvements. A friend who was undergoing treatment for leprosy advised her to go to FUNASA in Floriano for a sputum smear. She was, however, in need of a guide to request the exam by a health professional, so she went to a BHU in her municipality. The next day she returned with the request and they had a smear and the same day in the 
afternoon she received the positive result. She became desperate and returned home for comfort. She resigned herself to see a private physician, and soon learned that this treatment only existed in the public service, increasing her distress. She then went to BHU and started treatment for 12 months. She suffered a lot initially because her spots became more vivid and she felt a lot of pain in her body. The physician added another medication to improve. She finished treatment, but the scars remain to tell the story.

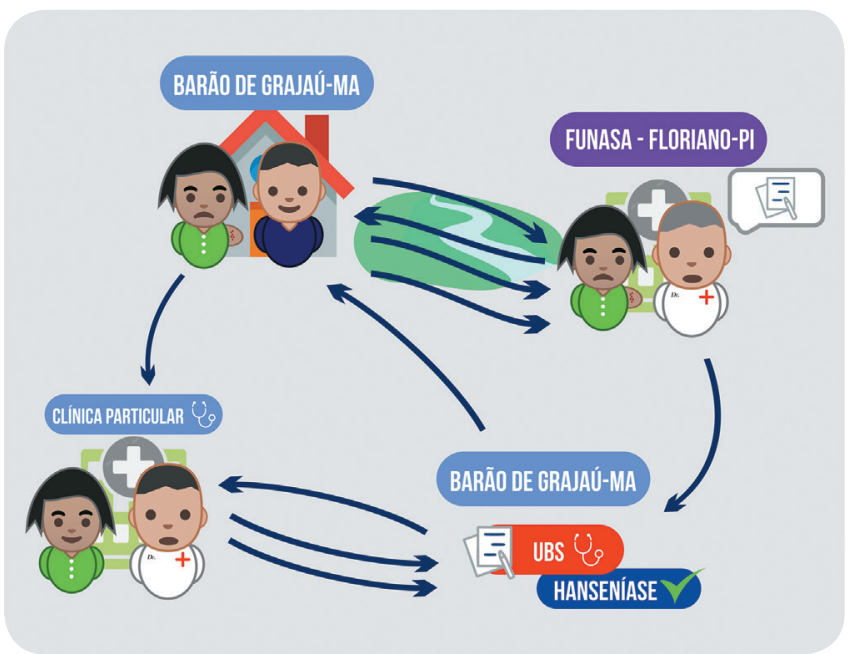

Figure 5 - P5's therapeutic itinerary

P6 - R.V.S. - 28 years old, female, single, complete high school, technical nursing course (ongoing), currently works as a cleaning assistant, Catholic, earns half a minimum wage, lives in her own seven-room house with three people.

TI P6 - It all started from a case in the family (sister) and prolonged contact, she had the disease and underwent treatment. She noticed a spot on her back and asked her sister to touch it, but she didn't feel the touch. She went to BHU and the physician requested sputum smears to be performed in Floriano. She returned with the result to the $\mathrm{BHU}$ physician, undergoing treatment throughout 2004. Seven years later, she felt her body itch before sleeping. Her residence had no electricity so it was only the next day that she could see what was bothering her. She noticed a lot of spots all over her body, but unfortunately it was the weekend and the only place she got care was at the city hospital. They gave her a painkiller and asked her to look for BHU on Monday (already suggesting a leprosy diagnosis), i.e., the weekend was all about malaise and anguish. On Monday, she went to BHU, a sputum smear was requested, again done in Floriano and on the same day she received a negative result, but the disease was present according to the professional. She started treatment, and, after six months, she stopped on her own for a month due to constant malaise. The $\mathrm{CHW}$ in the area sensitized her to the importance of continuing treatment and so she resumed taking self-administered daily doses for another six months. The periods of the two treatments were marked by prejudice and rejection.

P7 - C.A.R. - 34 years old, male, single, incomplete high school, canoeist (people crossing Parnaíba River that divides Maranhão and Piauí States), Catholic, earning a minimum wage, lives with his parents in a rented house with four rooms.

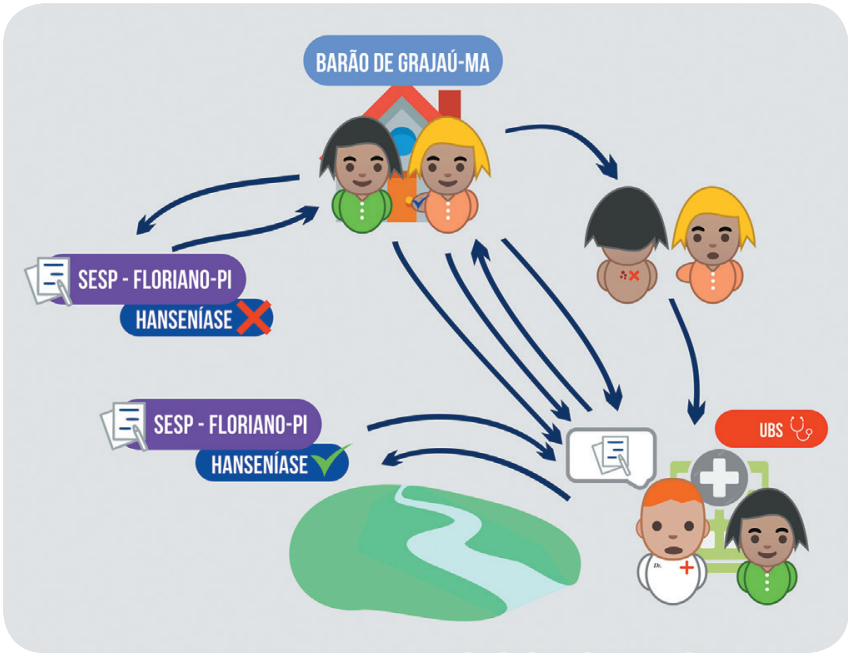

Figure 6 - P6's therapeutic itinerary

TI P7- In the beginning, he had a small spot, which grew, which made him look for a BHU. In consultation with the physician, several tests were performed with a needle, in the ear, and using test tubes with hot and cold water. The results were normal, so smear microscopy was performed, which was carried out in Floriano. The tests were negative, and the spot continued to increase. Only three years later, he sought another professional at a private clinic and he requested a biopsy that was positive for leprosy, having been referred to start treatment in Barão de Grajaú. After a few months of treatment, he supplemented with $20 \mathrm{mg}$ prednisone, as he was in a lot of pain. Even with the end of treatment, the injuries did not disappear, the concern continued and later, almost three years later, he looked for another professional who did not request any exam and referred him to restart treatment in 2016.

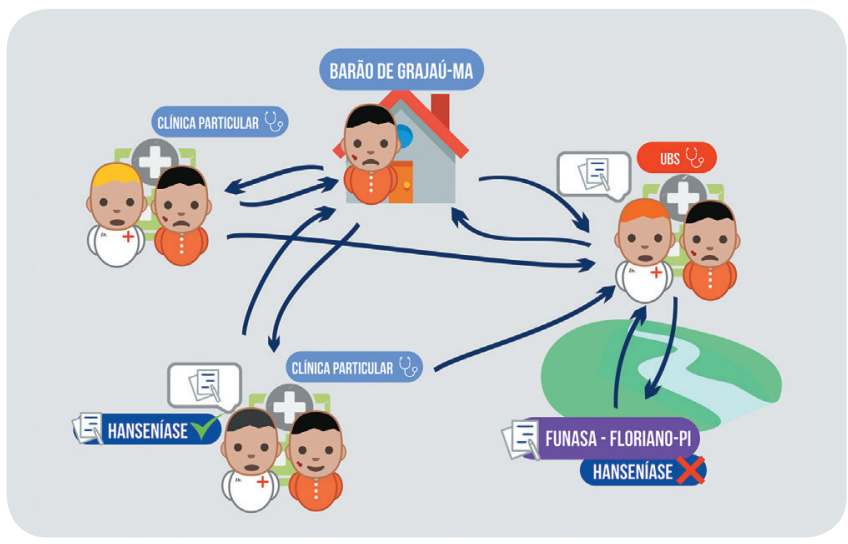

Figure 7 - P7's therapeutic itinerary

\section{DISCUSSION}

\section{Pilgrimage in the search for leprosy diagnosis: a long way}

Tls demonstrate that the search for diagnosis is configured as a major difficulty in accessing health services, which in most cases is long, resulting in a late diagnosis and consequently with the presence of visible deformities, reinforcing stigma associated with leprosy. 
We also emphasize that the difficulty of access is due to the population's lack of knowledge in relation to the signs and symptoms of the disease, the professionals' unpreparedness as well as the operational failures and the way of organizing health services in the municipality, being one of the barriers to care in leprosy.

Supporting our findings, the study conducted by Silva et al. ${ }^{(17)}$ highlights that the peculiar characteristics of the disease, its long incubation period and the insidious signs and symptoms associated with the operational deficiencies of services, the gaps in professional training and the difficult access to services provide a barrier to access for early diagnosis and timely treatment.

In a study carried out in Minas Gerais that investigated the trajectory of leprosy cases, it was shown that $73.9 \%$ of patients were unaware of the initial symptoms of leprosy, and that same number referred to a delay less than or equal to one month to get an appointment at unity ${ }^{(18)}$.

In the municipality studied, we noticed that BHUs do not have a flow or protocols for comprehensive treatment for people with leprosy, such as diagnostic suspicion, diagnosis and epidemiological investigation, nor is it configured as a gateway to the Brazilian Unified Health System (Sistema Único de Saúde), making it difficult for people with leprosy to access care. A similar situation is found in the study by Vieira et al. ${ }^{(19)}$, in which PHC performance in general is better when compared to leprosy control actions. However, despite the weaknesses, several studies point out the importance of integrating leprosy control actions in PHC, since it is considered a power in care for people affected by the disease ${ }^{(20-21)}$.

We also observed that most cases are referred to the referral unit to perform sputum smear microscopy, despite leprosy diagnosis being considered essentially clinical, when the Ministry of Health protocol recommends that the diagnosis should be made in $\mathrm{BHU}$, and only referred complex cases, such as recurrence, leprosy in children under 15 and leprosy reactions ${ }^{(22)}$.

$\mathrm{BHUs}$ are configured as the gateway to the health system; however, we noticed that users do not always look for this service first, as can be seen in the TI of participants 1, 2 and 3, who seek private services, even living in a municipality with FHS coverage, demonstrating the weakness of $\mathrm{PHC}$ for caring for people with leprosy.

The TIs described in our study demonstrated that when patients arrive at the services, with their anxieties after suspicions or incorrect therapies initially performed, they encounter professionals unprepared to welcome them and alleviate their doubts.

\section{Self-perception of clinical signs and suspicion of the disease by family and friends}

Leprosy diagnosis is essentially clinical, based on signs and symptoms and must be performed in PHC services through dermatoneurological examination ${ }^{(22)}$. In the Tls of our study, all people report that they noticed spots on their bodies, as the report by P1 points out "I was all painted, with some red things and itched".

However, they did not always find an early diagnosis when looking for a health service, leading to a delay in starting treatment, as we can evidence in TI when reporting that the diagnosis was only concluded by means of a sputum smear microscopy, which according to guidelines from the Ministry of Health can be given by dermatoneurological exam and treatment is instituted immediately ${ }^{(22)}$. Several studies indicate that PHC is the location chosen by patients when they suspect they have leprosy, but that in most cases they are referred to specialized services ${ }^{(20-21,23)}$.

In participants' narratives, the importance of family members and friends in the disease discovery was noticeable, similar to other studies that point out family involvement as of great relevance to care for people with leprosy ${ }^{(24)}$.

We found that in the case of the municipality in question, patients were referred to another service to perform tests and when they returned to the health unit, they received the prescribed treatment; however, the narratives do not provide these guidelines, this support from professionals in this difficult and transforming moment that is leprosy diagnosis. The earlier the diagnosis, the lesser the development of disabilities, which leave marks for life, perpetuating the stigma related to the disease.

\section{Leprosy marks: leprosy reactions as enhancers of illness}

Leprosy can cause leprosy reactions. They are acute events within a chronic disease, occurring between 25 to $30 \%$ of diagnosed cases, and are also responsible for the development of permanent physical disabilities ${ }^{(22,25)}$.

Leprosy reactions were also reported in this study, occurring in a symptomatic, localized or systemic manner, at different times (before, during, or after treatment). They brought inconvenience to these people, especially due to the difficulties of professionals to interpret these symptoms as reactive states of the disease, so that some situations were mistaken for reactivation of the bacillus, with guidance for new treatment, contributing to an even more distressing pilgrimage for users.

Considering its chronicity and the development of physical and psychosocial disabilities, people affected by leprosy will need constant care and vigilance, with access to other levels of complexity as a way of guaranteeing comprehensive care ${ }^{(7)}$.

In $\mathrm{Tl}$ users reported that when affected by leprosy reactions they are sent to another municipality. There are no referral services in the city, and they often need to use the private service, a situation that reveals a certain precariousness and lack of health responsibility, but also the pressing need to qualify access.

The pilgrimage of patients until reaching diagnosis was late or follow-up was inadequate, since, in the presence of leprosy reactions, they must be recognized and treated in a timely manner, with a view to promoting actions to prevent new episodes.

\section{Study limitations}

This study had as limitations the difficulty of patients to recall their trajectories in the search for care, in addition to discomfort when talking about a stigmatized disease that causes prejudice and discrimination. Thus, another factor to be considered was that it took place in only one of the municipalities in Maranhão State, so that this investigation in the others would be important even for an assessment of the effectiveness of primary care with a focus on leprosy, from the perspective of the elaboration of public policies that would qualify the state's actions in a global way. 


\section{Contributions to nursing, health, and public policies}

PHC is a field of nursing practice of great relevance in assisting people with leprosy. This study, through Tl's interpretations produced by users, can subsidize the development of more effective actions in the health system, allowing redirecting actions developed by FHS professionals, especially nurses, since they are considered care managers. TI-based studies contribute to the implementation of public policies aimed at people affected by leprosy, since it is possible to identify gaps in health services.

\section{FINAL CONSIDERATIONS}

The research made us see the marks that this disease can bring, hearing, seeing and feeling the realities of people who had leprosy and understanding how it was in their search for diagnosis and treatment.

The trajectory of patients was identified by the formal assistance networks: FHS and its professionals, private clinics and referral units. Social support networks were highlighted by family members.

In the city where the research is located, leprosy control actions need reformulations that seek the relationship between operational activities, epidemiological indicators and risk factors, in accordance with the real needs of each region. Thus, the gaps highlighted in TI stand out. Finally, the reality experienced by people with leprosy pointed out in the study exposes the obstacles that hinder access to health services.

Thus, issues such as availability, accessibility, institutional infrastructure, financial management and acceptability caused the search for diagnosis to be prolonged, delaying assistance.

\section{REFERENCES}

1. Fernandes MVC, Esteves AVF, Santos CB, Castro DB. Distribuição espacial e temporal da incidência da hanseníase em menores de 15 anos em Manaus. Enferm Bras 2019;18(2):264-72. doi: 10.33233/eb.v18i2.2469

2. Anchieta JJS, Costa LMM, Campos LC, Vieira MR, Mota OS, Morais Neto OL, et al. Trend analysis of leprosy indicators in a hyperendemic Brazilian state, 2001-2015. Rev Saude Publica. 2019;53:61. doi: 10.11606/S1518-8787.2019053000752

3. Levantezi M, Shimizu HE, Garrafa V. The principle of non-discrimination and non-stigmatization: reflections on leprosy. Rev Bioét. 2020;28(1):17-23. doi: 10.1590/1983-80422020281362

4. World Health Organization (WHO). Global leprosy strategy 2016-2020: Accelerating towards a leprosy-free world [Internet]. 2016 [cited 2018 Jul 20]. 20 p. Available from: http://apps.searo.who.int/PDS_DOCS/B5233.pdf

5. Ministério da Saúde (BR). Secretaria de Vigilância em Saúde. Hanseníase: boletim epidemiológico. [Internet]. 2018 [cited 2020 Mar 05];49(4). 11 p. Available from: https://www.saude.gov.br/images/pdf/2018/janeiro/31/2018-004-Hanseniase-publicacao.pdf

6. Ministério da Saúde (BR). Secretaria de Vigilância em Saúde. Hanseníase: boletim epidemiológico. [Internet]. 2020[cited 2020 Mar 02]; Número especial. 51 p. Available from: https://www.saude.gov.br/images/pdf/2020/janeiro/31/Boletim-hanseniase-2020-web.pdf

7. Silva JSR, Palmeira IP, Sá AMM, Nogueira LMV, Ferreira AMR. Fatores sociodemográficos associados ao grau de incapacidade física na hanseníase. Rev Cuid. 2018;9(3):2338-48. doi: 10.15649/cuidarte.v9i3.548

8. Leano HAM, Araújo KMFA, Rodrigues RN, Bueno IC, Lana FCF. Indicadores relacionados à incapacidade física e diagnóstico de hanseníase. Rev Rene. 2017;18(6):832-9. doi: 10.15253/2175-6783.2017000600018

9. Pereira TM, Silva LMS, Dias MAS, Monteiro LD, Silva MRF, Alencar OM. Temporal trend of leprosy in a region of high endemicity in the Brazilian Northeast. Rev Bras Enferm. 2019;72(5):1424-30. doi: 10.1590/0034-7167-2018-0682

10. Gerhardt TE, Pinheiro R, Ruiz ENF, Silva Jr AG. Itinerários terapêuticos: integralidade no cuidado, avaliação e formação em saúde. Rio de Janeiro: CEPESC / IMS/ UERJ ABRASCO; 2016. 437 p.

11. Silva NEK, Sancho LG, Figueiredo WS. Between flows and therapeutic projects: revisiting the notions of lines of care in health and therapeutic itineraries. Ciênc Saúde Coletiva. 2016;21(3):843-52. doi: 10.1590/1413-81232015213.08572015

12. Tong A, Sainsbury P, Craig J. Consolidated criteria for reporting qualitative research (COREQ): a 32-item checklist for interviews and focus groups. Int J Qual Health Care[Internet]. 2007 [cited 2020 May 07];19(6):349-57. Available from: http://cdn.elsevier.com/promis_misc/ISSM_COREQ_Checklist.pdf

13. Instituto Brasileiro de Geografia e Estatística (IBGE). Cidades: Barão de Grajaú, Maranhão [Internet]. 2020 [cited 2020 Mar 03]. Available from: https://cidades.ibge.gov.br/brasil/ma/barao-de-grajau/panorama

14. Muylaert CJ, Sarubbi Jr V, Gallo PR, Rolim Neto ML, Reis AOA. Narrative interviews: an important resource in qualitative research. Rev EsC Enferm USP. 2014;48(spe2):184-9. doi: 10.1590/S0080-623420140000800027

15. Minayo MCS. O desafio do conhecimento: pesquisa qualitativa em saúde. 12. ed. São Paulo: Hucitec, 2010.

16. Cabral ALV, Martinez-Hemáez A, Andrade EIG, Cherchiglia ML. Itinerários terapêuticos: o estado da arte da produção científica no Brasil. Ciênc Saúde Coletiva. 2011;16(11):4433-42. doi: 10.1590/S1413-81232011001200016

17. Silva JSR, Palmeira IP, Sá AMM, Nogueira LMV, Ferreira AMR. Variáveis associadas ao grau de incapacidade. Rev Cuid. 2019;10(1):e618. doi: 10.15649/cuidarte.v10i1.618

18. Laurindo CR, Vidal SL, Gama BMBM, Loures LF, Fernandes GAB, Coelho ACO. Trajetória de casos de hanseníase e fatores relacionados. Cienc Cuid Saude. 2018;17(3) e42275. doi: 10.4025/cienccuidsaude.v17i3.42275 
19. Vieira NF, Rodrigues RN, Niitsuma ENA, Lanza FM, Lana FCF. Avaliação da atenção primária: comparativo entre o desempenho global e as ações de hanseníase. Rev Enferm Cent O Min. [Internet]. 2019 [cited 2020 Mar 28];9(2896):2-8. Available from: http://seer.ufsj.edu.br/index. $\mathrm{php} / \mathrm{recom} / \mathrm{article} / \mathrm{view} / 2896$

20. Lanza FM, Vieira NF, Oliveira MMC, Lana FCF. Evaluation of the Primary Care in leprosy control: proposal of an instrument for users. Rev Esc Enferm USP. 2014;48(6):1054-61. doi: 10.1590/S0080-623420140000700013

21. Sousa GS, Silva RLF, Xavier MB. Atributos da atenção primária em saúde no controle da hanseníase: ótica do enfermeiro. Rev Baiana Enferm. 2017;31(1):1-10. doi: 10.18471/rbe.v31i1.17251

22. Ministério da Saúde (BR). Secretaria de Vigilância em Saúde. Diretrizes para vigilância, atenção e eliminação da hanseníase como problema de saúde pública, com a finalidade de orientar os gestores e os profissionais dos serviços de saúde: Portaria MS/GM n. 149, de 3 de fevereiro de 2016. Brasília, DF: Ministério da Saúde; 2016.

23. Silva MCD, Paz EPA. Nursing care experiences with Hansen's disease patients: contributions from hermeneutics. Acta Paul Enferm. 2017;30(4):435-41. doi: 10.1590/1982-0194201700064

24. Barbosa JC, Ramos Jr AN, Alencar OM, Pinto MSP, Castro CGJ. Atenção pós-alta em hanseníase no Sistema Único de Saúde: aspectos relativos ao acesso na região Nordeste. Cad Saude Coletiva. 2014;22(4):351-8. doi: 10.1590/1414-462X201400040008

25. Alencar MJF, Barbosa JC, Pereira TM, Santos SO, Eggens KH, Helkelbach J. Leprosy reactions after release from multidrug therapy in an endemic cluster in Brazil: patient awareness of symptoms and self-perceived changes in life. Cad Saúde Colet. 2013;21(4):450-6. doi: $10.1590 / \mathrm{S} 1414-462 X 2013000400014$ 